\title{
Os desafios e as possibilidades de trabalho com as TIC no ensino da Matemática em escolas públicas da Zona da Mata Mineira
}

\section{The challenges and the possibilities of work with ICT in the teaching of Mathematics in public schools in the Zona da Mata Mineira}

\begin{abstract}
Thais Aparecida Pacheco Instituto Federal de Educação, Ciência e Tecnologia do Sudeste de Minas Gerais (IF Sudeste MG) Campus Rio Pomba, Departamento Acadêmico de Matemática, Física e Estatística

Rio Pomba, MG, Brasil thaispacheco11@yahoo.com.br

Paula Reis de Miranda Instituto Federal de Educação, Ciência e Tecnologia do Sudeste de Minas Gerais (IF Sudeste MG) Campus Rio Pomba, Departamento Acadêmico de Matemática, Física e Estatística

Rio Pomba, MG, Brasil paula.reis@ifsudestemg.edu.br
\end{abstract}

\begin{tabular}{l}
\hline Informações do Artigo \\
\hline (C) (i) \& \\
\hline
\end{tabular}

Histórico do Artigo

Submissão: 6 de fevereiro de 2018. Aceite: 7 de julho de 2018.

Palavras-chave

Tecnologias da Informação e

Comunicação

Formação de Professores de

Matemática

Escolas Públicas

\section{Resumo}

Neste trabalho investigou-se as possibilidades e condições necessárias para que os professores de Matemática possam trabalhar com as Tecnologias de Informação e Comunicação (TIC) nas escolas públicas da Zona da Mata Mineira. São sujeitos da pesquisa os professores de Matemática das escolas públicas estaduais e municipais das cidades de Ubá, Tocantins e Visconde do Rio Branco, todas situadas na Zona da Mata do Estado de Minas Gerais. Para esses sujeitos foi então aplicado um questionário semiestruturado com a finalidade de obter informações a respeito da presença e utilização das TIC no ensino de Matemática. Após a pesquisa e a análise dos dados concluiu-se que para se trabalhar com as TIC nas aulas de Matemática, não basta que as escolas tenham um laboratório e equipamentos e esse ambiente não é suficiente para um trabalho efetivo e permanente dos docentes. São apontadas questões financeiras, burocráticas e de formação docente que precisam ser vistas com certa urgência para a efetivação do uso das tecnologias na prática docente, bem como são apresentados diferentes modos de seu uso ou não uso na construção de significados e no desenvolvimento de novas aprendizagens matemáticas.

\section{Abstract}

In this work, we investigated the possibilities and necessary conditions for teachers of Mathematics can work with Information and Communication Technologies (ICT) in public schools in the Zona da Mata, Minas Gerais. Are subjects of the research Mathematics teachers working in state and municipal public schools of the cities of Ubá, Tocantins and Visconde do Rio Branco, all located in the Zona da Mata in the State of Minas Gerais. For these subjects, a semistructured questionnaire was applied with the purpose of obtaining information about the presence and use of ICT in Mathematics teaching. After researching and analyzing the data, it was concluded that in order to work with ICT in mathematics classes, it is not enough that schools have a laboratory and equipment and this environment is not enough for an effective and permanent work of teachers. It is pointed out financial, bureaucratic and also teacher training issues that need to be seen with some urgency for the effective use of technologies in teaching practice, as well as different modes of their use or no use in the construction of meanings and in the development of new mathematical learning. 


\title{
1. Introdução
}

As mudanças que vêm acontecendo na sociedade devido ao advento da tecnologia são tão amplas que implicam em repensar e reavaliar a atual conjuntura da educação como um todo nos diversos níveis e formas. De acordo com Borba e Penteado (2010), as "tecnologias informáticas"1 têm possibilitado que um número cada vez maior de pessoas tenha acesso às informações que antes eram essencialmente adquiridas na escola. Hoje já existem cursos sobre diferentes assuntos disponíveis em vídeos, revistas, cds, internet, canais etc.

Percebe-se que as escolas, bem como todo o sistema educacional, estão diante de novos desafios, buscando estratégias para um ensino de qualidade e para o desenvolvimento de uma aprendizagem significativa e efetiva no contexto de uma sociedade cada vez tecnológica e digital. Em virtude disso, há necessidade de encontrar recursos para o motivar os alunos para aprenderem os conteúdos curriculares, em meio as tecnologias disponíveis, pois se o aluno não quiser aprender, dificilmente, ocorrerá uma aprendizagem significativa e efetiva. Segundo a Base Nacional Comum Curricular (BNCC) "as experiências das crianças em seu contexto familiar, social e cultural, suas memórias, seu pertencimento a um grupo e sua interação com as mais diversas tecnologias de informação e comunicação são fontes que estimulam sua curiosidade" (BRASIL, 2016, p. 56) e consequentemente favorecem novas aprendizagens.

Nesta conjuntura, no final do século XX, as Tecnologias de Informação e Comunicação (TIC) se desenvolvem e se difundem, sendo uma alternativa para o desenvolvimento de conteúdos escolares, em diferentes contextos (BICUDO, 1999; BORBA; PENTEADO, 2010; KENSKI, 2012). Os Parâmetros Curriculares Nacionais (PCN) (BRASIL, 1998) já orientavam a incorporação das tecnologias na sala de aula. A BNCC reafirma a importância do uso das tecnologias pois

\begin{abstract}
Há que se considerar, ainda, que a cultura digital tem promovido mudanças sociais significativas nas sociedades contemporâneas. Em decorrência do avanço e da multiplicação das tecnologias de informação e comunicação e do crescente acesso a elas pela maior disponibilidade de computadores, telefones celulares, tablets e afins, os estudantes estão dinamicamente inseridos nessa cultura, não somente como consumidores. Os jovens têm se engajado cada vez mais como protagonistas da cultura digital, envolvendo-se diretamente em novas formas de interação multimidiática e multimodal e de atuação social em rede, que se realizam de modo cada vez mais ágil. Por sua vez, essa cultura também apresenta forte apelo emocional e induz ao imediatismo de respostas e à efemeridade das informações, privilegiando análises superficiais e o uso de imagens e formas de expressão mais sintéticas, diferentes dos modos de dizer e argumentar característicos da vida escolar. (BRASIL, 2016, p. 59).
\end{abstract}

Entretanto, observa-se que muitos docentes não fazem uso das TIC no ensino dos conteúdos curriculares. Diante desse cenário e preocupados com essa situação, investigou-se as seguintes questões: Os professores de Matemática das escolas estaduais da Zona da Mata Mineira

\footnotetext{
1 Termo usado pelo autor para designar as ferramentas tecnológicas utilizadas em um determinado meio (sistema), representada a partir da existência dos softwares, vídeo e teleconferências, bem como o uso da internet.
} 
têm acesso às TIC? Esses docentes têm se apropriado das TIC e utilizando-as como ferramentas educacionais?

Desse modo, objetivo geral desta pesquisa é investigar as possibilidades e condições necessárias para que os professores de Matemática possam trabalhar, ou não, com as TIC nas escolas públicas, segundo a investigação de escolas da Zona da Mata do estado de Minas Gerais. Ressalta-se que não se tem o objetivo de investigar como os professores utilizam, ou não, as TIC, mas de verificar se, ainda no século XXI, muitos docentes não as utilizam no ensino da Matemática e assim propor uma breve reflexão sobre a importância de seu uso na construção de significados e no desenvolvimento de novas aprendizagens.

\section{Contexto da Investigação}

As unidades amostrais selecionadas para a investigação foram os professores de Matemática de quatro escolas públicas das cidades de Ubá, Tocantins e Visconde do Rio Branco, todas localizadas na região Zona da Mata do estado de Minas Gerais. Essas escolas apresentam grande porte (mais de 1000 estudantes) e oferecerem Ensino Fundamental, Ensino Médio e Ensino Técnico. No decorrer no artigo as escolas serão nomeadas, respectivamente, por Escola A, B, C e D.

Por se tratar de escolas de grande porte, a razão entre a quantidade de estudantes matriculados e o número de professores de Matemática é elevado, conforme é mostrado na Tabela 1.

Tabela 1 - Quantidade aproximada de alunos e número de professores de Matemática.

\begin{tabular}{cccc}
\hline Escola & $\begin{array}{c}\text { Número aproximado de } \\
\text { alunos }\end{array}$ & $\begin{array}{c}\text { Número de professores de } \\
\text { Matemática }\end{array}$ & Relação aluno/professor \\
\hline A & 1700 & 10 & 170,00 \\
B & 1850 & 11 & 168,18 \\
C & 1000 & 09 & 111,11 \\
D & 1000 & 05 & 200,00 \\
\hline
\end{tabular}

Fonte: Dados da pesquisa.

A partir desses dados é possível verificar que há um número expressivo de alunos por professores, acarretando um nível de dificuldade ainda maior para os professores no planejamento das aulas como na utilização das TIC nas escolas onde trabalham.

Esta pesquisa foi restrita as escolas de setor público justamente onde toda a população tem acesso a essa rede de ensino e é acessível a todos independente da classe social, raça, cor, religião etc. A escolha das escolas públicas está relacionada ao fato das mesmas apresentarem uma realidade escolar diferente daquela existente nas escolas da rede privada de ensino, mais especificamente por dois motivos: primeiro, no que se refere à situação socioeconômica da escola e da clientela escolar que delas faz parte e, segundo, a quantidade e variedade de recursos 
financeiros, incluindo aqueles que viabilizam os recursos tecnológicos disponíveis a serem utilizados por seus professores e alunos.

No que diz respeito às semelhanças, pode-se dizer que as escolas pesquisadas apresentam características comuns quanto o seu espaço físico interno e externo. Ressalta-se que das escolas pesquisadas, apenas uma escola não possui laboratório de informática. De modo geral, todas as dependências internas das escolas são bem espaçosas, arejadas, iluminadas e limpas. O espaço físico interno de todas as escolas é amplo e agradável. Esse espaço é composto de várias salas de aula, banheiros, secretaria, salas de TV e vídeo, biblioteca, sala dos professores, quadra coberta para realização de atividades desportivas e um laboratório de informática.

A pesquisa empírica foi realizada junto ao corpo docente (professores de Matemática) das Escolas A, B, C e D, distribuídos conforme a Tabela 2.

Tabela 2 - Quantidade de participantes da pesquisa por escolas.

\begin{tabular}{ccccccc}
\hline Participantes da pesquisa de campo & Escola A & Escola B & Escola C & Escola D & Total \\
\hline Professores de Matemática & 04 & 07 & 04 & 04 & 19 \\
\hline
\end{tabular}

Fonte: Dados da pesquisa.

Para esses sujeitos foi então elaborado um questionário semiestruturado ${ }^{2}$ para o grupo de participantes da pesquisa - Professores de Matemática da rede pública - com a finalidade de obter informações a respeito da presença e utilização da TIC no ensino de Matemática.

Percorreram-se, então, durante os meses de abril, maio e junho de 2017 , as escolas investigadas para aplicação dos questionários semiestruturados (SANTOS, 2011) com os participantes da pesquisa. Os dados foram coletados via questionário aplicado presencialmente aos sujeitos e, posteriormente, analisados à luz da análise de caráter qualitativo e quantitativo em Educação Matemática (BORBA; ARAÚJO, 2006) e da teoria de análise do discurso (ORLANDI, 2003). Vale ressaltar que a análise quantitativa foi auxiliada por ferramentas editoras de planilhas de dados.

\section{Análise e Discussão}

Neste tópico, são apresentadas as informações e a análise dos dados coletados com a aplicação dos questionários aos professores participantes da pesquisa. Para isso, discute-se algumas transcrições das respostas, mantendo-se em sua forma original e descrevendo-as em fonte itálica com destaque de aspas (“...”).

A investigação teve a participação de 19 professores de Matemática, 89,5\% sexo feminino e $10,5 \%$ do sexo masculino, todos licenciados em Matemática e $63 \%$ deles com curso de especialização.

2 O questionário proposto continha 16 perguntas que buscam investigar: a formação dos docentes, as condições físicas da escola, os conhecimentos docentes sobre TIC, seus anseios e preocupações sobre o seu uso, ou não, no trabalho docente. 
Ao pensar em tecnologia, tentou-se demarcar o recorte temporal de formação dos docentes sujeitos dessa pesquisa, uma vez que se tem vivido em tempos modernos ${ }^{3}$ de uma sociedade cada vez mais tecnológica e o professor é desafiado constantemente a rever e ampliar seu conhecimento (BRASIL, 2016). Nesse sentido, a Tabela 3 apresenta as décadas de formação dos professores de Matemática atuantes nas escolas pesquisadas:

Tabela 3 - Ano término da graduação dos professores.

\begin{tabular}{cc}
\hline Ano término da Graduação & Número de professores \\
\hline Anterior a 1990 & 4 \\
Entre 1990 e 2000 & 4 \\
Entre 2000 e 2010 & 5 \\
Entre 2010 e $2017^{4}$ & 6 \\
\hline
\end{tabular}

Fonte: Dados da pesquisa.

Pode-se verificar que $71,4 \%$ dos professores pesquisados possui formação anterior a 2010 . Essa situação revela que a grande maioria não esteve em contato com as transformações tecnológicas durante sua escolarização, em especial em sua infância, adolescência e juventude. Segundo Kenski (2012), as velozes transformações tecnológicas da atualidade impõem novos ritmos e dimensões à tarefa de ensinar e aprender. É preciso estar em permanente estado de aprendizagem e de adaptação ao novo. Não existe mais a possibilidade de considerar a pessoa totalmente formada, independentemente do grau de escolarização alcançado.

Questionados sobre sua formação no curso de Licenciatura em Matemática e as possíveis disciplinas cursada com o foco no uso da TIC em sala de aula, a maioria dos professores respondeu que não cursaram, mas gostariam de ter cursado disciplinas com esse enfoque. Bicudo (1999), ainda no século passado, levanta a questão de que é preciso que o professor, desde sua formação inicial, tanto nas licenciaturas quanto nos cursos de magistério, tenha a possibilidade de interagir com o computador de forma diversificada e, também, de discutir criticamente questões relacionadas com as transformações influenciadas pela informática, sobretudo nos estilos de conhecimento e nos padrões de interação social.

Após a investigação desses primeiros dados, o olhar investigativo se volta para a escola e suas condições para o trabalho docente com TIC para o ensino de Matemática. Pode-se elencar nas tabelas abaixo, a partir das respostas dos docentes, as condições físicas para o uso de recursos tecnológicos, os recursos tecnológicos disponíveis e os softwares e as ferramentas tecnológicas que estão disponíveis nas escolas pesquisadas.

\footnotetext{
${ }^{3}$ Referência ao cenário crítica de "modernidade" e do capitalismo exploratório no filme TEMPOS MODERNOS (Modern Times, EUA 1936, DIREÇÃO: Charles Chaplin, ELENCO: Charles Chaplin, Paulette Goddard, 87 min. preto e branco, Continental) e aqui relacionado à estrutura social cada vez mais acelerada que também oprimi o trabalhador docente.

${ }^{4}$ É interessante ressaltar que os sete professores pertencentes a esse intervalo foram graduados até o ano de 2015.
} 
Tabela 4 - Condições físicas para o uso de recursos tecnológicos sob a visão dos professores de Matemática.

\begin{tabular}{cc}
\hline Condições físicas para o uso de recursos tecnológicos & Escolas \\
\hline Laboratório de informática com mais de 20 máquinas disponível aos estudantes & A, B, C e D \\
Computadores disponíveis para os professores & A, B e C \\
Internet disponível para os estudantes & B \\
Internet disponível para os professores & A, B e C \\
\hline
\end{tabular}

Fonte: Dados da pesquisa.

De acordo com a Tabela 4 é possível observar que, segundo os professores, a escola B apresenta todas as condições físicas listadas acima, enquanto a escola $\mathrm{C}$ apresenta somente uma. Isso nos mostra que, apesar das escolas serem estaduais, pertencerem à mesma superintendência estadual de ensino, terem mais de mil estudantes matriculados, ainda assim há desigualdades de dispobilização de ambientes e materiais que favoreçam a criação de espaços que estimulem a TIC no ambiente escolar.

Já a tabela 5 traz as informações trazidas pelos docentes sobre recursos tecnológicos disponíveis nas escolas.

Tabela 5 - Recursos tecnológicos disponíveis nas escolas sob a visão dos professores de Matemática.

Recursos tecnológicos disponíveis

Escolas

\begin{tabular}{cc}
\hline $\begin{array}{c}\text { Softwares educacionais para os estudantes } \\
\text { Softwares educacionais para os professores } \\
\text { Projetor data show }\end{array}$ & C \\
Televisor & A, B, C e D \\
Notebook ou computador para uso em sala de aula & A, B, C e D \\
Caixas de som ou aparelho de som & A, B, C e D \\
Calculadoras & A, B, C e D \\
\hline
\end{tabular}

Fonte: Dados da pesquisa.

A partir desses dados percebe-se que todas as escolas pesquisadas possuem equipamentos tecnológicos - projetor data show, televisor e caixas de som ou aparelho de som porém, foi encontrada apenas uma escola pesquisada com softwares educacionais para os estudantes e professores. Vale destacar que o número de equipamentos disponíveis não corresponde ao número de turmas/salas de aula, o que demanda de um rodízio entre professores para o agendamento e utilização dos mesmos em seu trabalho docente.

Todavia, um dos professores investigados destacou que apesar da dificuldade em ter acesso a tais equipamentos, ele se viu diante da necessidade de aquisição de ferramentas tecnológicas para trabalhar com a TIC em suas aulas e os adquiriu com recurso próprio para minimizar tais problemas: "Diante da falta de recursos para se trabalhar com a TIC nas escolas públicas estaduais, 
o professor que deseja trabalhar com essas tecnologias, acaba utilizando recursos próprios. No meu caso, já trabalhei em escolas que tinha data show e notebook disponíveis, porém não era autorizada a sua utilização em sala de aula pelos professores. Devido à essa situação, acabei adquirindo os materiais para poder trabalhar em sala de aula com os alunos." (Professor D3).

Quando questionados sobre o nível de conhecimento sobres as TIC, obtive-se o gráfico da Figura 1 como resposta.

Figura 1 - Nível de conhecimento sobre a TIC.

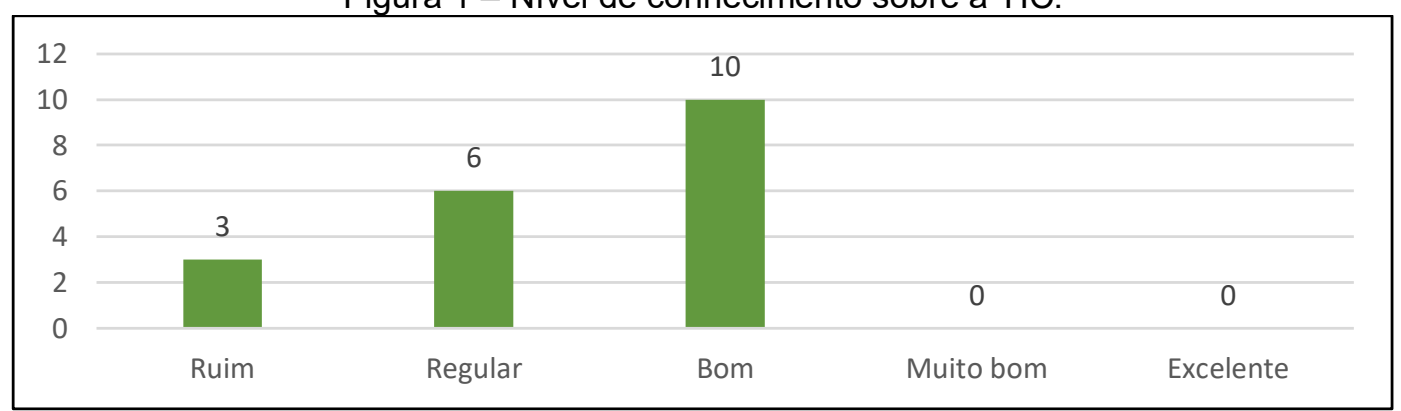

Fonte: Dados da pesquisa.

Pode-se perceber que alguns professores $(47,36 \%)$ tem um baixo nível de conhecimento sobre as TIC. Essa situação nos leva à reflexão de que

É preciso que esse profissional tenha tempo e oportunidade de familiarização com as novas tecnologias educativas, suas possibilidades e seus limites, para que, na prática, faça escolhas conscientes sobre o uso das formas mais adequadas ao ensino de um determinado tipo de conhecimento, em um determinado nível de complexidade, para um grupo específico de alunos e no tempo disponível (KENSKI, 2012, p. 48-49).

Mesmo diante dessa pouca familiaridade dos professores com softwares educacionais, decidiu-se por investigar o conhecimento dos professores em relação a ferramentas e softwares matemáticos (Figura 2).

Figura 2 - Softwares e ferramentas tecnológicas que os professores já utilizaram.

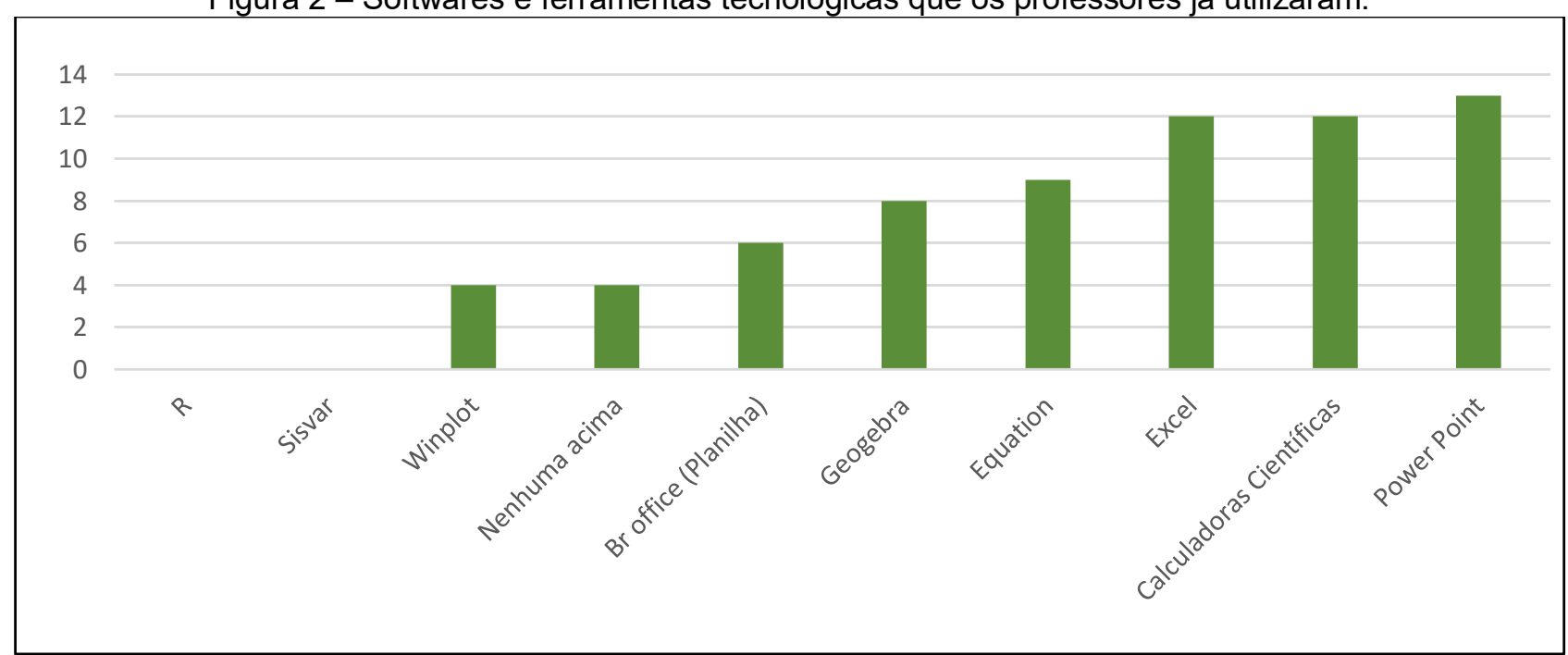

Fonte: Dados da pesquisa. 
A partir do gráfico da Figura 2 percebeu-se que os softwares que os professores dominam na sua maioria são o Power Point, Calculadoras Científicas, Excel, Equation e GeoGebra, sendo que quatro professores $(21,1 \%)$ não dominam nenhum dos softwares citados, constatando ainda que esses professores tiveram o término da graduação anterior ao ano 2000. Segundo Kenski (2012) é necessário, sobretudo, que os professores se sintam confortáveis para utilizar esses novos auxiliares didáticos. Estar confortável significa conhecê-los, dominar os principais procedimentos técnicos para sua utilização, avaliá-los criticamente e criar novas possibilidades pedagógicas, partindo da integração desses meios com o processo de ensino.

Já em relação aos softwares e as ferramentas tecnológicas que estão disponíveis na escola, encontrou-se que em apenas uma escola esse recurso está disponível, mas perguntados novamente e oferecendo alternativas para escolha encontrou-se como resposta os dados da Tabela 6.

Tabela 6 - Softwares e ferramentas tecnológicas disponíveis nas escolas sob a visão dos professores de Matemática.

\begin{tabular}{cc}
\hline Softwares e ferramentas tecnológicas & Escolas \\
\hline Equation & A e B \\
Geogebra & A \\
Br office (planilha) & A e B \\
Excel & A, B e C \\
Power Point & A, B e C \\
Calculadoras científicas & C \\
Nenhuma citada & C \\
\hline
\end{tabular}

Fonte: Dados da pesquisa.

Foi encontrado também um desconhecimento por parte do corpo de professores das escolas sobre o que seriam softwares ou ferramentas tecnológicas. Entretanto, as Escolas A e B oferecem alguns dos softwares e ferramentas tecnológicas, mas ainda há escolas que não oferecem nenhum desses recursos.

Foram feitas perguntas discursivas sobre se os professores já utilizaram as TIC em suas aulas (Tabela 7 ).

Tabela 7 - Professores que utilizaram ou nunca utilizaram a TIC em suas aulas.

\begin{tabular}{cccc}
\hline Escola & Total de professores pesquisados & Sim & Não \\
\hline A & 04 & 02 & 02 \\
B & 07 & 01 & 06 \\
C & 04 & 02 & 02 \\
D & 04 & 01 & 03 \\
Total & 19 & 06 & 13 \\
\hline
\end{tabular}

Fonte: Dados da pesquisa. 
Pode-se concluir que a maior parte dos professores $(68,4 \%)$ nunca utilizaram as TIC em suas aulas, mas por outro lado observa-se que pelo menos um professor de cada escola já utilizou as TIC como recurso pedagógico em suas aulas e ainda que esses professores tiveram sua formação posteriormente ao ano de 2000. Moran et al. (2000) defendem que cada docente pode encontrar sua forma mais adequada de integrar as várias tecnologias e os muitos procedimentos metodológicos. Nesse sentido é importante que estes ampliem e que aprendam a dominar e a fazer uso das formas de comunicação interpessoal/grupal e de comunicação audiovisual/telemática.

Além de questionar se o professor já utilizou a TIC em suas aulas, investigou-se, em caso afirmativo, qual TIC foi utilizada, como foram utilizadas e quais foram os objetivos. Foram encontradas várias respostas apontando o uso do projetor:

"Foi utilizado o projetor data show como apoio às aulas, com o objetivo de facilitar as aulas e torná-las mais atraentes." (Professor $\mathrm{A} 1^{5}$ ).

"Foi utilizado o projetor data show, com a utilização dos vídeos, para que os alunos assimilem o conteúdo de uma maneira diferente." (Professor A2).

"Foram utilizados o projetor data show, notebook e televisor para introdução de conteúdos com o objetivo de dar aulas diferenciadas." (Professor C1).

Apesar dessa indicação, o uso de projetor não caracteriza uma mudança nas aulas tradicionais, todavia, alguns professores indicaram a utilização de outros recursos tecnológicos com diferentes finalidades. A primeira finalidade apresentada foi a utilização do calculado do modo tradicional (Professor B1), porém, a segunda finalidade está diretamente relacionada com a intenção de utilização desses recursos de modo diferente do tradicional (Professor D1).

"Foram utilizadas as calculadoras, em atividades onde sugeriam o uso dessa ferramenta com o objetivo de mostrar aos estudantes como usar essa ferramenta de forma correta." (Professor B1).

"Foram utilizados o Power Point, Excel, calculadora científica, Winplot e Geogebra em sala de aula, só o professor manuseando. O Power Point utilizado na apresentação de definições e conteúdos, Excel utilizado na tabulação de dados estatísticos, calculadoras utilizadas nas operações e o Winplot e Geogebra no estudo de funções, gráfico e geometria. Com o objetivo de permitir maior visualização e compreensão dos conceitos estudados e favorecer a realização de atividades diferenciadas." (Professor D1).

Ainda a esse respeito foi identificado um professor que estudou sobre o uso das TIC em sala de aula e este defende que é "[...] completamente a favor da TIC em sala de aula, inclusive em uma das minhas especializações a monografia falava exatamente desse assunto." (Professor A2). Nessa fala fica também evidenciada a importância da formação continuada dos docentes, em especial aqui

\footnotetext{
${ }^{5}$ Para utilização das falas dos professores, destaca-se a utilização da letra para indicar a escola e o número para indicar o professor.
} 
os professores de Matemática, e um espaço para a participação destes em eventos científicos e de capacitação.

Os professores que nunca utilizaram as TIC apresentam as diferentes justificativas que envolvem desde ausência de recursos tecnológicos até falta de formação.

"Não temos computadores disponível para alunos." (Professor A1).

"Não tenho treinamento, por isso não domino as TIC's." (Professor B1).

"Falta de material e espaço físico para um número maior de alunos." (Professor B2).

"Falta de tempo para preparar algo novo para levar para a sala de aula." (Professor B3).

"Dificuldade em preparar aula que promova realmente aprendizado em determinado conteúdo." (Professor C1).

"Tem laboratório de informática e os demais citados no item 8 mais não funciona." (Professor D1).

"Falta de dispositivos." (Professor D3).

Os obstáculos enfrentados pelos professores em suas escolas para o uso das TIC, além de falta de recurso são as principais justificativas para o não trabalho com as TIC nas aulas de Matemática, como relatam os professores:

"Nossa escola é muito grande com 17 salas de aula por turno e temos que revezar no uso dos equipamentos que não são muitos." (Professor A1), além da "[...] falta de computadores para que se possa trabalhar com uma sala inteira." (Professor A2).

"O número excessivo de alunos em sala e o currículo extenso." (Professor B1), e ainda "Não temos notebook ou computador nas salas de aula e muito menos internet." (Professor B2).

"Falta de recursos e ambientes adequados. Na escola em que trabalho, desde a reforma em 2016, não foi disponibilizado o laboratório de informática para os alunos, na sala dos professores há um computador que não funciona desde essa data. A reforma já terminou, mas até hoje esses recursos não foram providenciados." (Professor D1).

Observa-se que a falta de recursos tecnológicos ou disponibilidades dos mesmos e a infraestrutura ainda constituem um grande obstáculo a ser superado pelas escolas. Segundo Borba e Penteado (2010), em relação à infraestrutura é preciso pensar no apoio técnico. Um técnico em informática deveria fazer parte do quadro de funcionários das escolas. É preciso um suporte constante e alguém que assuma essa responsabilidade de ajudar o professor no seu dia a dia.

Quando questionados sobre o uso das TIC em sala de aula para a disciplina que eles lecionam, todos concordam que, apesar de não incorporarem essa metodologia às aulas, é uma ótima e importante ferramenta de ensino aprendizagem para os dias de hoje, e ainda ressaltam:

"Acho ótimo uma vez que traz a realidade para a sala de aula, tornando as aulas mais atrativas saindo um pouco das aulas orais." (Professor A1).

"Muito importante" (Professor A2) e "ajudaria muito no processo de ensino e aprendizagem." (Professor A3). 
"Sempre é necessário visualizar para uma melhor compreensão, por isso em qualquer disciplina é importante o uso das TIC's." (Professor B1) e ainda "É uma boa e nova proposta que ajudará no processo de ensino." (Professor B2).

"É uma ferramenta que pode contribuir e complementar o ensino de conteúdos de Matemática. Além de ser uma maneira alternativa para tornar as aulas mais atraentes e produtivas." (Professor C1).

"Acredito que as TIC's sejam de fundamental importância, uma vez que favorecem um ambiente de mediação, interação, visualização e aprendizagem. Através das TIC's é possível proporcionar situações, onde o aluno é motivado a observar, levantar hipóteses, conjecturar, generalizar e formalizar conceitos." (Professor D1).

Assim, segundo Kenski (2012), um novo tempo, um novo espaço e outras maneiras de pensar e fazer educação são exigidos na sociedade da informação. O amplo acesso e o amplo uso das novas tecnologias condicionam a reorganização dos currículos, dos modos de gestão e das metodologias utilizadas na prática educacional. Para tanto torna-se importante, enquanto educadores matemáticos, pensarmos - nos incluímos nessa intenção - na mobilidade tecnológica, em especial com a crescente adesão de jovens pelo uso de celulares e tablets, dando assim diferentes sentidos e significados para os espaços formais (laboratórios) e desenvolvendo novas potencialidades para os recursos tecnológicos trazidos pelos principais sujeitos da aprendizagem.

\section{Considerações Finais}

O desenvolvimento do presente estudo possibilitou uma análise dos desafios e possibilidades de se trabalhar com a TIC no ensino da Matemática nas escolas públicas da cidade de Ubá e região. Além disso, também permitiu uma pesquisa de campo para obter dados mais consistentes sobre a realidade dessas escolas públicas quanto aos recursos tecnológicos existentes para utilização como recurso pedagógico nas aulas, sob a visão dos professores.

Em relação às escolas pesquisadas, verificou-se que em algumas ainda não há condições físicas necessárias para o uso de recursos tecnológicos como recurso pedagógico. Porém todas as escolas pesquisadas contam com um acervo mínimo de recursos tecnológicos como projetor data show, televisor, notebook ou computador para uso em sala de aula e caixas de som ou aparelho de som.

Pode-se concluir que a maior parte dos professores nunca utilizou a TIC em suas aulas, mesmo que tenha sido encontrado pelo menos um professor de cada escola que afirme ter utilizado e ou fazer uso das TIC como recurso pedagógico.

Nesse estudo encontrou-se uma maioria de professores afirmando ser importante o uso das TIC no processo de ensino e aprendizagem da Matemática em sala de aula, mas estes acabam não utilizando a TIC como uma ferramenta de trabalho devido a diversos fatores, que variam desde a 
falta dos equipamentos necessários, o despreparo e dificuldades dos professores para manuseio das TIC, falta de tempo para preparar aulas até à falta de suporte para auxiliar os professores.

Os professores que utilizam as TIC em seu ambiente de trabalho afirmam que estas podem ser um auxílio nas aulas, ajudando o professor a trabalhar de maneira diferenciada e estimulando a aprendizagem dos alunos, pois elas podem permitir maior visualização e compreensão dos conceitos estudados e favorecer a realização de atividades diferenciadas.

Assim, infere-se que os desafios a serem percorridos e superados são grandes devido aos fatores já expostos. Não se pode descartar que as possibilidades de recursos tecnológicos existentes, não são as ideais, mas é necessário um pontapé inicial por parte da gestão escolar na promoção de cursos de aperfeiçoamento e capacitação de professores e ainda de suporte e condições para os professores. Estes cursos podem ser firmados com instituições externas à escola (institutos federais, faculdades, universidades etc.) ou serem fomentados pelos próprios docentes que já dominam e utilizam essas tecnologias.

Vale ressaltar que esses docentes, em especial os mais antigos, necessitam de encorajamento e motivação para lidar com diversas situações com esses recursos no dia a dia.

Espera-se com este trabalho e com sua divulgação, que os educadores da rede estadual de ensino possam usufruir dessa pesquisa servindo como uma motivação para uma melhor atuação no seu campo de trabalho por meio das TIC. Consequentemente, ainda que, num futuro não muito distante, as escolas estejam equipadas e os professores preparados, reconhecendo assim, a necessidade de uma formação básica e social do estudante. Fazendo das diferenças a possibilidade para a criação de uma nova proposta de ensino e de uma aprendizagem significativa para um cidadão crítico e transformador da sociedade.

\section{Referências}

BICUDO, Maria Aparecida Viggiani. Pesquisa em Educação Matemática: Concepções e Perspectivas. São Paulo: Editora UNESP, 1999.

BORBA, Marcelo de Carvalho; ARAÚJO, Jussara de Loiola. Pesquisa qualitativa em Educação Matemática. 2. ed. Belo Horizonte: Autêntica, 2006.

BORBA, Marcelo de Carvalho; PENTEADO, Miriam Godoy. Informática e Educação Matemática. 4. ed. Belo Horizonte: Autêntica, 2010.

BRASIL. Secretaria de Educação Fundamental. Parâmetros Curriculares Nacionais: Matemática/Secretaria de Educação Fundamental. - Brasília: MEC/SEF,1998.

BRASIL. Ministério da Educação. Secretaria da Educação Básica. Base nacional comum curricular. Brasília, DF, 2016. Disponível em: <http://basenacionalcomum.mec.gov.br/site/inicio>. Acesso em: jun. 2018.

KENSKI, Vani Moreira. Tecnologias e Ensino Presencial e a Distância. 9. ed. Campinas, SP: Papirus, 2012. 
MORAN, José Manuel; MASETTO, Marcos Tarciso; BEHRENS, Marilda Aparecida. Novas tecnologias e mediação pedagógica. 16. ed. Campinas: Papirus, 2000.

ORLANDI, Eni P. Análise de discurso: princípios e procedimentos. 5. ed. Campinas: Pontes, 2003.

SANTOS, Marcos Pereira dos. Recursos Didático-Pedagógicos na Educação Matemática Escolas - Uma abordagem teórico-prática. Rio de Janeiro: Editora Ciência Moderna Ltda, 2011. 